\title{
Announcements
}

\section{Extracranial Optic Nerve Decompression}

November 6 and 7, 1993, Boston

A meeting to discuss extracranial optic nerve decompression for traumatic optic neuropathy and to plan a multicenter, randomized, prospective trial.

Information:

Michael P. Joseph, MD Massachusetts Eye and Ear Infirmary 243 Charles Street Boston, MA 02214-3096 (USA)

Phone 617-573-3192 Fax 617-573-3914

Research on Hair Testing for Drugs of Abuse

Program Announcement No. PA-92-18, November 1, 1991 to November 1, 1994

Department of Health and Human Services, Public Health Service, National Institutes of Health, National Institute on Drug Abuse, Research Grants Program

The National Institute on Drug Abuse (NIDA) has an interest in research on the utility of hair as a specimen for the detection of drugs of abuse. The goals of this program are to encourage systematic research on the use of hair testing to detect drugs of abuse in an accurate and reliable manner, and to develop the necessary procedures and safeguards. Specific areas of interest are: pharmacological studies, analytical studies, and cost/beneñt ratio analyses.

29th Postgraduate Course in Ear Surgery

April 10 to April 15, 1994, Nijmegen, The Netherlands

For further information and registration form, please write to:

Prof. Dr. P. van den Broek

University Hospital Nijmegen

Department of Otorhinolaryngology

PO Box 9101

NL-6500 HB Nijmegen (The Netherlands)

Fax:80-540251

Further information may be obtained from

Rao S. Rapaka, PhD, or M. Beth Grigson Babecki. MA Division of Basic Research National Institute on Drug Abuse 5600 Fishers Lane, Rm. 10A-31 Rockville, MD 20857 (USA)

Phone (301) 443-6975

NIDA will accept grant applications in response to this announcement through November 1, 1994. 